\title{
INFLUÊNCIA DO TAMANHO E DA PROCEDÊNCIA DE SEMENTES DE Mimosa caesalpiniifolia Benth. SOBRE A GERMINAÇÃO E VIGOR ${ }^{1}$
}

\author{
Edna Ursulino Alves², Riselane de Lucena Alcântara Bruno ${ }^{3}$, Ademar Pereira de Oliveira ${ }^{3}$, Adriana \\ Ursulino Alves ${ }^{4}$; Anarlete Ursulino Alves ${ }^{5}$ e Rinaldo Cesar de Paula ${ }^{6}$
}

\begin{abstract}
RESUMO-Mimosa caesalpiniifolia Benth. é uma planta nativa da Região Nordeste que vem sendo progressivamente cultivada do Maranhão ao Rio de Janeiro. A planta apresenta grande potencial para arborização, cerca viva e produção de madeira. O presente trabalho teve como objetivo avaliar a influência da procedência e tamanho das sementes sobre a germinação e vigor. Para tanto, realizou-se um experimento no Laboratório de Análise de Sementes do Centro de Ciências Agrárias da Universidade Federal da Paraíba (CCA-UFPB), em Areia, PB, em delineamento experimental inteiramente casualizado com os tratamentos distribuídos em esquema fatorial 3x3, com os fatores procedência (Areia, Usina e Arara) e classes de tamanho (sementes pequenas, médias e grandes), em quatro repetições de 25 sementes. Foram analisadas as seguintes características: peso de 100 sementes, dimensões das sementes (comprimento, largura e espessura), porcentagem, primeira contagem e velocidade de germinação, comprimento e massa seca da raiz primária e hipocótilo e massa seca dos cotilédones. Constatou-se que a germinação não foi influenciada pelo tamanho das sementes, no entanto, ela foi significativamente influenciada pela procedência. Os testes de primeira contagem e de velocidade de germinação não se mostraram adequados para avaliação do vigor das sementes, sendo este mais bem avaliado pela massa seca dos cotilédones e hipocótilo. O vigor das sementes, apresentou relação direta com o seu tamanho, justificando-se a adoção de classes de tamanho para a formação de mudas.
\end{abstract}

Palavras-chave: Localidades, dimensões de sementes, testes de vigor e classes de tamanho.

\section{INFLUENCE OF SIZE AND PROVENANCE ON THE GERMINATION AND VIGOR OF Mimosa caesalpiniifolia Benth. SEEDS}

\begin{abstract}
Mimosa caesalpiniifolia Benth. is a native species from the Northeast region, Brazil, which has been increasingly cultivated from the States of Maranhão to Rio de Janeiro. It presents great potential for urban forestry, hedging and wood production. The present research had as objective to evaluate the influence of the provenance and seed size on the germination and vigor of Mimosa caesalpiniifolia Benth. An experiment was conducted at the Laboratory of Seed Analysis of CCA-UFPB, Areia, Paraíba State, Brazil in a completely randomized design with the treatments arranged in a $3 \times 3$ factorial, with three provenances and three size classes, four replicates of 25 seeds. The following characteristics were analyzed: 100-seed weight, seed dimensions, percentage and first counting, germination speed, length and weight of dry matter of primary root and hypocotyl and weight of cotyledon dry matter. It was verified that the germination was not influenced by seed size, however, it was influenced strongly by the provenance. The tests of first count and germination speed were not shown appropriate for seed vigor evaluation, being this better appraised by cotyledon and hypocotyl dry matter. Seed vigor was directly related with size, being thus justified the use of size classes for seedling production.
\end{abstract}

Keywords: Sites, seed dimensions, vigor tests and size classes.

\footnotetext{
${ }^{1}$ Recebido em 20.07.2004 e aceito para publicação em 10.08.2005.

${ }^{2}$ Bolsista DCR, CNPq, CCA-UFPB, C. Postal 2, 58397-000 Areia-PB. E-mail: <ursulinoalves@ hotmail.com>

${ }^{3}$ Departamento de Fitotecnia do CCA-UFPB, Areia-PB.

${ }^{4}$ Programa de Pós-Graduação em Agronomia do CCA-UFPB, Areia-PB.

${ }^{5}$ Graduação em Agronomia do CCA-UFPB, Areia-PB.

${ }^{6}$ Departamento de Produção Vegetal da FCAV/UNESP e Bolsista do CNPq. Jaboticabal; Via de Acesso Prof. Paulo Donato Castellane, s/n, 14884-900 Jaboticabal-SP. E-mail: <rcpaula@ fcav.unesp.br>
} 


\section{INTRODUÇÃO}

Mimosa caesalpiniifolia Benth. é uma planta que se propaga totalmente por via sexuada, no entanto há grande heterogeneidade no formato, coloração e tamanho das sementes. A importância da $M$. caesalpiniifolia na Região Nordeste caracteriza-se pela resistência à seca, crescimento rápido (RIBASKI et al., 1983), obtenção de madeira (DRUMOND, 1982) e como planta ornamental, sendo na Região Sudeste bastante utilizada como cerca-viva (LORENZI, 2000). A folhagem constitui importante fonte de forragem, fresca ou fenada, para alimentação do gado e, principalmente, para os caprinos, particularmente na época de escassez de chuvas (MENDES, 1989; VASCONCELOS, 1997; LEAL JÚNIOR et al., 1999).

A classificação das sementes por tamanho, para determinação da qualidade fisiológica, tem sido bastante empregada na multiplicação das diferentes espécies vegetais (FRAZÃO et al., 1983). As sementes de maior tamanho geralmente foram mais bem nutridas durante o seu desenvolvimento, possuindo embriões bem formados e com maior quantidade de substâncias de reserva, sendo, consequientemente, as mais vigorosas (CARVALHO e NAKAGAWA, 2000). Popinigis (1985) comentou que o tamanho da semente, em muitas espécies, é indicativo de sua qualidade fisiológica, e as sementes pequenas, dentro de um mesmo lote, apresentam menor germinação e vigor do que as médias e grandes. Complementando, Gray et al. (1986) comentaram que as sementes maiores supostamente seriam as que receberam maior quantidade de assimilados durante o seu desenvolvimento, apresentando embriões bem formados, com maiores quantidades de reserva, sendo, potencialmente, as mais vigorosas.

A influência do tamanho das sementes sobre a qualidade fisiológica tem sido pesquisada com certa intensidade em várias espécies, porém é pouco freqüente em espécies florestais. A separação das sementes por classes de tamanho para determinação da qualidade fisiológica, através de testes de germinação e vigor, tem sido bastante empregada, visando encontrar a classe ideal para multiplicação das diversas espécies vegetais (TORRES, 1994). Os resultados obtidos em grande parte das experiências obedecem a uma regra, mais ou menos geral, de que, quanto maior o peso da semente, melhor será a germinação e o vigor (FRAZÃO et al., 1985; CARNEIRO, 1985).

\section{R. Árvore, Viçosa-MG, v.29, n.6, p.877-885, 2005}

Nos testes que avaliaram características das plântulas, as sementes menores, por necessitarem de menor quantidade de água, foram as primeiras a germinar (KRZYZANOWSKI et al., 1999). Contudo, Frazão et al. (1983) constataram que sementes grandes e médias de Paullinia cupana var. sorbilis (Mart.) Ducke exibiram melhor emergência e velocidade de emergência do que aquelas de menor tamanho. Resultados semelhantes foram obtidos por Gonzalez (1993), com sementes de Virola koschnyi Warb.

As sementes maiores produzem plântulas mais vigorosas, provavelmente porque possuem maior quantidade de material de reserva, maior nível de hormônios e maior embrião (SURLES et al., 1993). Maior quantidade de reserva aumenta a possibilidade de sucesso no estabelecimento da plântula, uma vez que possibilita a sua sobrevivência por um tempo maior em condições ambientais que, ainda, não permitem o aproveitamento das reservas nutricionais e hídricas do solo e a realização da fotossíntese (HAIG e WESTOBY, 1991). Frazão et al. (1985) observaram que sementes mais pesadas de cacau originaram plantas, cuja altura e diâmetro do caule foram superiores aos daquelas originadas de sementes médias, que, por sua vez, superaram as plantas oriundas de sementes leves.

Gonzalez (1993), Surles et al. (1993) e Leishman e Westoby (1994) relataram que sementes de maior tamanho têm sido correlacionadas com maiores taxas de crescimento inicial de plântulas, o que, segundo Gross (1984), aumentaria a probabilidade de sucesso durante o estabelecimento destas, uma vez que o rápido crescimento de raiz e parte aérea possibilitariam à planta aproveitar as reservas nutricionais e hídricas do solo e realizar a fotossíntese.

Rêgo et al. (1991) verificaram que sementes grandes de Macadamia integrifolia Maiden \& Betche não apresentaram melhor desempenho germinativo. Resultados semelhantes foram obtidos por Aguiar et al. (1996), que não encontraram influência do tamanho sobre a germinação de sementes de Caesalpinia echinata Lam.

Isso posto, o presente trabalho teve por objetivo verificar o efeito do tamanho e da procedência de sementes de M. caesalpiniifolia sobre a germinação e o vigor.

\section{MATERIAL E MÉTODOS}

O trabalho foi realizado no Laboratório de Análise de Sementes do Centro de Ciências Agrárias da Universidade Federal da Paraíba, em dezembro de 2001, 
com sementes de Mimosa caesalpiniifolia colhidas de 20 árvores, em três municípios (Areia, Usina e Arara) do Estado da Paraíba. Os frutos de coloração café (MUÑOZ et al., 1993) foram colhidos diretamente das árvores e beneficiados manualmente. $\mathrm{O}$ beneficiamento constou da abertura dos frutos para obtenção das sementes, com eliminação daquelas malformadas. Após o beneficiamento, as sementes foram separadas visualmente em três classes de tamanho (pequenas, médias e grandes) e, em seguida, pesadas em balança analítica com precisão de 0,001 g. O teor de água, determinado pelo método da estufa a $105 \pm 3{ }^{\circ} \mathrm{C} / 24$ horas, das sementes pequenas, médias e grandes oriundas de Areia foi de 6,7; 8,0; e 10,3\%, de Usina de 9,0;10,3; e $10,4 \%$ e de Arara de 8,$8 ; 9,2$; e $10 \%$, respectivamente.

As dimensões das sementes (comprimento, largura e espessura) foram determinadas com o auxílio de paquímetro digital e o peso de 100 sementes, de acordo com a metodologia descrita por Brasil (1992) para o peso de 1000 sementes.

O teste de germinação foi instalado em substrato entre papel, na temperatura de $30^{\circ} \mathrm{C}$ constante, em caixa plástica transparente de $11 \times 11$ x $3 \mathrm{~cm}$, com tampa, em quatro repetições de 25 sementes e fotoperíodo de oito horas de luz e 16 de escuro. O papel foi umedecido com água destilada na quantidade equivalente a 2,5 vezes o seu peso de matéria seca. As contagens foram feitas diariamente, considerando-se germinadas as sementes com raiz primária com pelo menos $2 \mathrm{~cm}$ de comprimento. De posse do número de sementes germinadas diariamente, avaliaram-se as seguintes características: primeira contagem da germinação - correspondente à porcentagem acumulada de sementes germinadas até o terceiro dia após o início do teste, conforme Martins et al. (1992); índice de velocidade de germinação (IVG) - determinado de acordo com a fórmula apresentada por Maguire (1962); germinação - consideraramse, ao final do teste (oito dias), as plântulas normais que apresentavam as estruturas essenciais perfeitas (Brasil, 1992); comprimento da raiz primária e hipocótilo - no final do teste de germinação, as plântulas normais de cada repetição foram medidas com o auxílio de uma régua graduada em centímetros, sendo os resultados expressos em centímetros; massa seca da raiz primária, hipocótilo e cotilédones das plântulas - submetendo-se as plântulas normais, obtidas na contagem final do teste de germinação, a secagem em estufa regulada a $80^{\circ} \mathrm{C}$ por 24 horas, com posterior pesagem em balança analítica com precisão de $0,001 \mathrm{~g}$. Os resultados foram expressos grama/raiz primária, hipocótilo e cotilédone, conforme recomendações de Krzyzanowski et al. (1999).

A análise estatística dos dados foi realizada, segundo o delineamento experimental inteiramente casualizado, com os tratamentos distribuídos em esquema fatorial $3 \times 3$, com os fatores procedências (Areia, Usina e Arara) e classes de sementes (pequenas, médias e grandes). Os dados foram submetidos à análise de variância, sem transformações, e as médias comparadas pelo teste de Tukey a $5 \%$ de probabilidade, quando houve significância no teste F.

\section{RESULTADOS E DISCUSSÃO}

Quanto ao peso de 100 sementes e à sua espessura, houve interação significativa entre tamanho de sementes e localidades, constatando-se maior peso para as sementes grandes nas três localidades. Nas classes de tamanho grandes e médias, as sementes provenientes de Areia foram as mais pesadas sem, contudo, diferir das oriundas de Arara, nas médias. Nas sementes pequenas não houve diferenças de peso entre as três localidades. Também, independentemente da localidade, as sementes grandes apresentaram maior peso que as médias e estas, por sua vez, maior peso que as pequenas (Tabela 1). Resultados semelhantes foram obtidos por Castro e Dutra (1997) com sementes de Leucaena leucocephala (Lam.) de Wit, em que aquelas de maior tamanho exibiram maior peso de 100 sementes.

Na classe de sementes pequenas, as provenientes de Areia apresentaram menor espessura que as de Usina; nas de tamanho médio, as de Usina tiveram menor espessura que as de Areia e Arara, e entre as sementes grandes não houve diferenças na espessura entre as localidades (Tabela 1). Ferreirae Torres (2000) não verificaram diferenças na espessura das sementes de Acacia senegal (L.) de Willd, de diferentes tamanhos. Nas sementes de Areia e de Arara, as pertencentes à classe de tamanho pequenas foram as de menor espessura e, nas de Usina, as sementes grandes foram mais espessas que as pequenas e estas, que as médias. As correlações positivas e significativas entre o tamanho com o peso de 100 sementes $(\mathrm{r}=0,99 * *)$ e a espessura das sementes $(r=0,72 * *)$ indicam certa influência das classes de tamanho sobre essas características (Tabela 2).

R. Árvore, Viçosa-MG, v.29, n.6, p.877-885, 2005 
Tabela 1 - Peso e espessura de sementes de Mimosa caesalpiniifolia Benth. provenientes de diferentes localidades e com diferentes tamanhos

Table 1 - Weigh and thickness of Mimosa caesalpiniifolia Benth. seeds derived from different sites and with different sizes

\begin{tabular}{|c|c|c|c|c|c|c|}
\hline \multirow{3}{*}{$\begin{array}{l}\text { Classes de } \\
\text { Tamanhos }\end{array}$} & \multicolumn{3}{|c|}{ Peso de 100 Sementes (g) } & \multicolumn{3}{|c|}{ Espessura (mm) } \\
\hline & \multicolumn{6}{|c|}{ Localidades } \\
\hline & Areia & Usina & Arara & Areia & Usina & Arara \\
\hline Pequenas & $25,9 \mathrm{cA}^{1}$ & $27,3 \mathrm{cA}$ & $26,0 \mathrm{cA}$ & $1,52 \mathrm{bB}$ & $1,57 \mathrm{bA}$ & $1,55 \mathrm{bAB}$ \\
\hline Médias & $38,0 \mathrm{bA}$ & $36,0 \mathrm{bB}$ & $36,8 \mathrm{bAB}$ & $1,62 \mathrm{aA}$ & $1,53 \mathrm{cB}$ & $1,61 \mathrm{aA}$ \\
\hline Grandes & $50,2 \mathrm{aA}$ & $47,0 \mathrm{aB}$ & $46,7 \mathrm{aB}$ & $1,65 \mathrm{aA}$ & $1,62 \mathrm{aA}$ & $1,63 \mathrm{aA}$ \\
\hline
\end{tabular}

${ }^{1}$ Médias seguidas pela mesma letra minúscula na coluna e maiúscula na linha não diferem entre si, pelo teste de Tukey a $5 \%$.

Tabela 2 - Coeficientes de correlação simples (r) entre o tamanho das sementes com as características avaliadas

Table 2 - Coefficients of simple correlation ( $r$ ) between seed size and the appraised characteristics

\begin{tabular}{lc}
\hline Características Avaliadas & $\mathrm{r}$ \\
\hline Comprimento & $0,98 * *$ \\
Largura & $0,70 * *$ \\
Espessura & $0,72 * *$ \\
Peso de 100 sementes & $0,99 * *$ \\
Germinação & $-0,07 \mathrm{~ns}$ \\
Primeira contagem & $-0,09$ ns \\
IVG & $-0,67 * *$ \\
Comprimento da raiz primária & $0,90 * *$ \\
Comprimento do hipocótilo & $-0,01{ }^{\mathrm{ns}}$ \\
Massa seca da raiz primária & $0,92 * *$ \\
Massa seca do hipocótilo & $0,96 * *$ \\
Massa seca dos cotilédones & $0,97 * *$ \\
\hline 1** valor significativo a 1\% e ${ }^{2 \mathrm{~ns}}$ valor não-significativo pelo teste F.
\end{tabular}

Houve, apenas, efeito isolado das classes de tamanho e localidades sobre o comprimento e a largura das sementes (Tabela 3). Verificou-se maior comprimento e largura nas sementes grandes, seguidas das médias e, por último, das pequenas. Tal comportamento também foi observado por Ferreira e Torres (2000), em sementes de Acacia senegal (L.) de Willd. As sementes de Arara apresentaram menor comprimento que as de Areia e Usina, porém, quanto à largura das sementes, não houve diferenças entre as localidades. Foram constatadas correlações positivas e significativas entre o tamanho e o comprimento $(\mathrm{r}=0,98 * *)$ e a largura $(\mathrm{r}=0,70 * *)$ das sementes (Tabela 2). Biruel (2001) enfatizou a importância de se classificarem as sementes através de suas dimensões, observando que em Caesalpinia ferrea Mart. ex. Tul. var. leiostachya Benth. as sementes de maior largura tiveram melhor comportamento germinativo.
Tabela 3 - Comprimento e largura de sementes de Mimosa caesalpiniifolia Benth. provenientes de diferentes localidades e com diferentes tamanhos

Table 3 - Length and width of Mimosa caesalpiniifolia Benth. seeds derived from different sites and with different sizes

\begin{tabular}{lcc}
\hline Localidades & Comprimento $(\mathrm{mm})$ & Largura $(\mathrm{mm})$ \\
\hline Areia & $6,21 \mathrm{a}^{1}$ & $5,65 \mathrm{a}$ \\
Usina & $6,27 \mathrm{a}$ & $5,64 \mathrm{a}$ \\
Arara & $6,09 \mathrm{~b}$ & $5,68 \mathrm{a}$ \\
\hline Classes de tamanhos & & \\
Pequenas & $5,41 \mathrm{c}$ & $4,84 \mathrm{c}$ \\
Médias & $6,24 \mathrm{~b}$ & $5,84 \mathrm{~b}$ \\
Grandes & $6,92 \mathrm{a}$ & $6,29 \mathrm{a}$ \\
\hline
\end{tabular}

${ }^{1}$ Médias seguidas pela mesma letra não diferem entre si, pelo teste de Tukey a $5 \%$.

Na primeira contagem de germinação (Tabela 4), os maiores valores ocorreram nas sementes médias, entre as oriundas de Areia, nas sementes médias e pequenas, entre as de Usina, e sementes pequenas e grandes provenientes de Arara. Castro e Dutra (1997) observaram maior porcentagem de germinação em sementes de Leucaena leucocephala, por ocasião da primeira contagem, naquelas de peso intermediário. No entanto, em Euterpe edulis Mart a germinação foi mais rápida em sementes de maior tamanho (MARTINS et al., 2000). Entre as sementes pequenas, as provenientes de Areia, entre as médias, as oriundas de Arara, e entre as grandes, aquelas de Usina e Areia, apresentaram os menores valores de primeira contagem.

No IVG (Tabela 4), não foi verificado diferença estatística entre os diferentes tamanhos das sementes provenientes de Areia. Naquelas oriundas de Usina, os maiores valores foram obtidos nas sementes pequenas e, naquelas originadas de Arara, a maior velocidade de germinação ocorreu nas sementes pequenas e médias. $\mathrm{O}$ fato de as sementes de menor tamanho apresentarem maior velocidade de germinação, está de acordo com 
as observações de Krzyzanowski et al. (1999), que relataram que sementes menores, por necessitarem de menor quantidade de água, são as primeiras a germinar. Em sementes de Macadamia integrifolia (RÊGO et al., 1991) e de Acacia senegal (L.) de Willd (FERREIRA e TORRES, 2000), o IVG não foi afetado pelo tamanho das sementes.

Resultados divergentes foram obtidos com sementes de Paullinia cupana (FRAZ̃̃O et al., 1983), de Eucalyptus grandis Hill ex Maiden (BARBOSA e CAMPELLO, 1985) e de Eucalyptus maculata Hook (SILVA et al., 1994), em que as sementes maiores apresentaram índices de velocidade de germinação superiores aos daquelas de menor tamanho. Brown e Mayer (1986) relataram que o IVG nem sempre consegue identificar as diferenças entre lotes ou tratamentos, podendo resultar em valores semelhantes de subamostras de sementes com comportamento distinto quanto ao vigor. No presente trabalho, os testes de primeira contagem e de IVG não se mostraram adequados para avaliação das sementes das diferentes classes de tamanho. Esse comportamento pode ser explicado através da correlação negativa entre o tamanho das sementes e a primeira contagem $\left(r=-0,09^{\text {ns }}\right)$ e o IVG $(\mathrm{r}=-0,67 * *)($ Tabela 2$)$.

Com relação à germinação, constataram-se efeito apenas das localidades (Tabela 5) e correlação negativa, mas não-significativa, com o tamanho $\left(r=-0,07^{\text {ns }}\right)$ (Tabela 2). Os maiores porcentuais de germinação foram obtidos com as sementes oriundas de Arara, que não diferiu estatisticamente daquelas provenientes de Areia.

O tamanho também não afetou a germinação de sementes de Pesudotsuga menziesse (CLAIR e ADAMS, 1991), Macadamia integrifolia (RÊGO et al., 1991),
Aracacia xanthorriza Banc. (SEDIYAMA et al., 1991), Virola koschnyi (GONZALEZ, 1993), Acacia senegal (L.) de Willd (TORRES, 1994), Euterpe edulis Mart (ANDRADE et al., 1996) e de Leucaena leucocephala (Lam.) de Wit (CASTRO e DUTRA, 1997). No entanto, em Euterpe edulis Mart, Fleig e Rigo (1998) verificaram que os frutos-sementes médios exibiram maior percentual de germinação, seguidos pelos pequenos e pelos grandes.

Lin (1986) com Euterpe edulis Mart e Martins et al. (2000) com Euterpe espiritosantensis Fernandes constataram que os maiores valores de germinação foram significativamente mais elevados para frutossementes grandes. Também, Aguiar et al. (1996) observaram que a germinação das sementes grandes de Caesalpinia echinata foi aproximadamente três vezes maior que a das pequenas. Frazão et al. (1983), Barbosa e Campello (1985), Silva et al. (1994) e Biruel (2001), à semelhança dos outros autores, também verificaram influência do tamanho das sementes de Paullinia cupana, Eucalyptus maculata Hook, Eucalyptus grandis e Caesalpinia ferrea, respectivamente, sobre sua germinação.

Tabela 5 - Germinação de sementes de Mimosa caesalpiniifolia Benth. provenientes de diferentes localidades e com diferentes tamanhos

Table 5 - Germination of Mimosa caesalpiniifolia Benth. seeds derived from different sites and with different sizes

\begin{tabular}{lc}
\hline Localidades & Germinação $(\%)$ \\
\hline Areia & $94,00 \mathrm{ab}^{1}$ \\
Usina & $91,00 \mathrm{~b}$ \\
Arara & $97,00 \mathrm{a}$ \\
\hline
\end{tabular}

${ }^{1}$ Médias seguidas pela mesma letra não diferem entre si, pelo teste de Tukey a $5 \%$.

Tabela 4 - Primeira contagem e índice de velocidade de germinação (IVG) de sementes de Mimosa caesalpiniifolia Benth. provenientes de diferentes localidades e com diferentes tamanhos

Table 4 - First count and index of germination speed (IVG) of Mimosa caesalpiniifolia Benth. seeds derived from different sites and with different sizes

\begin{tabular}{|c|c|c|c|c|c|c|}
\hline \multirow{3}{*}{$\begin{array}{l}\text { Classes de } \\
\text { Tamanhos }\end{array}$} & \multicolumn{3}{|c|}{ Primeira Contagem (\%) } & \multicolumn{3}{|c|}{ IVG } \\
\hline & \multicolumn{6}{|c|}{ Localidades } \\
\hline & Areia & Usina & Arara & Areia & Usina & Arara \\
\hline Pequenas & $69,00 \mathrm{bB}^{1}$ & $79,00 \mathrm{abAB}$ & $84,00 \mathrm{aA}$ & $14,00 \mathrm{aC}$ & 20,39 aA & $17,04 \mathrm{aB}$ \\
\hline Médias & 87,00 aA & 81,00 aA & $70,00 \mathrm{bB}$ & $13,44 \mathrm{aB}$ & $16,72 \mathrm{bA}$ & 15,64 aA \\
\hline Grandes & $72,00 \mathrm{bB}$ & $71,00 \mathrm{bB}$ & 83,00 aA & $12,41 \mathrm{aA}$ & $12,28 \mathrm{cA}$ & $13,54 \mathrm{bA}$ \\
\hline
\end{tabular}

${ }^{1}$ Médias seguidas pela mesma letra, minúscula na coluna e maiúscula na linha não diferem entre si, pelo teste de Tukey a 5\%. 
As médias do comprimento da raiz primária e do hipocótilo encontram-se nas Tabelas 6 e 7. Os maiores valores de comprimento da raiz primária foram encontrados nas sementes provenientes de Arara, que não diferiram daquelas oriundas de Areia. Com relação às classes de tamanho das sementes, estes valores foram maiores nas sementes grandes (Tabela 6). Resultados semelhantes foram obtidos por Ferreira e Torres (2000), ao verificarem que o comprimento médio da raiz primária e das plântulas aumentou com o tamanho da semente. Também, houve correlações positiva e significativa $(r=0,90 * *)$ entre o tamanho das sementes e o comprimento da raiz primária (Tabela 2).

No tocando ao comprimento do hipocótilo (Tabela 7), os maiores valores foram obtidos nas sementes médias em Areia, sementes pequenas e médias em Usina e médias e grandes em Arara. Khare e Satpute (1999) observaram que as plântulas de Cajanus cajan (L.) Mill sp foram influenciadas significativamente pelo tamanho das sementes. Também, as sementes maiores de Theobroma cacao L. (FRAZÃO et al., 1985) e de Euterpe edulis Mart

Tabela 6 - Comprimento da raiz primária de plântulas de Mimosa caesalpiniifolia Benth. provenientes de diferentes localidades e com diferentes tamanhos

Table 6 - Length of primary root of Mimosa caesalpiniifolia Benth. seedlings derived from different sites and with different sizes

\begin{tabular}{lc}
\hline Localidades & Comprimento da Raiz Primária $(\mathrm{cm})$ \\
\hline Areia & $8,35 \mathrm{ab}^{1}$ \\
Usina & $8,04 \mathrm{~b}$ \\
Arara & $8,65 \mathrm{a}$ \\
\hline Classes de tamanhos & \\
Pequenas & $6,94 \mathrm{c}$ \\
Médias & $8,41 \mathrm{~b}$ \\
Grandes & $9,69 \mathrm{a}$ \\
\hline
\end{tabular}

${ }^{1}$ Médias seguidas pela mesma letra não diferem entre si, pelo teste de Tukey a $5 \%$.
(ANDRADE et al., 1996; FLEIG e Rigo, 1998) originaram plântulas mais vigorosas.

Na Tabela 8 são apresentados os resultados de massa seca da raiz primária e de cotilédones e, na Tabela 9 , os de massa seca do hipocótilo. Os maiores valores de massa seca da raiz primária e cotilédones (Tabela 8) foram obtidos com as sementes grandes, nas três localidades. Não houve influência das localidades sobre a massa seca do hipocótilo (Tabela 9), porém sementes grandes originaram plântulas com maior massa seca do hipocótilo, seguidas por sementes médias e por último, pelas sementes pequenas. Frazão et al. (1985), com sementes de Theobroma cacao L.; Silva et al. (1994), com sementes de Eucalyptus maculata Hook; Castro e Dutra (1997), com sementes de Leucaena leucocephala (Lam.) de Wit; e Fleig e Rigo (1998), com frutos-sementes de Euterpe edulis Mart, obtiveram os maiores valores de massa seca de plântulas originadas de sementes de maior tamanho. No entanto, em Acacia senegal (L.) de Willd, Torres (1994) não verificou influência do tamanho das sementes sobre o peso de matéria seca da parte aérea.

A importância do tamanho da semente baseia-se no fato de que aquelas maiores produzem plântulas mais vigorosas, presumivelmente porque possuem mais material de reserva, maior nível de hormônioe maiorembrião(SURLES et al., 1993). A maior diferenciação do vigor das sementes, pelo teste de massa seca das plântulas, baseia no fato de esse ser um teste com capacidade de detectar pequenas diferenças em vigor de sementes devidas ao genótipo, de tamanho da semente e ao local de produção, entre outros fatores (AOSA, 1983).

No presente trabalho, as correlações significativas entre o tamanho das sementes e a massa seca de raiz primária, de cotilédones e do hipocótilo (Tabela 2) indicam que tais características podem ser eficientes para detectar diferenças de vigor entre as classes de tamanho.

Tabela 7 - Comprimento do hipocótilo de plântulas de Mimosa caesalpiniifolia Benth. provenientes de diferentes localidades e com diferentes tamanhos

Table 7 - Length of hypocotyl of Mimosa caesalpiniifolia Benth. seedlings derived from different sites and with different sizes

\begin{tabular}{|c|c|c|c|}
\hline \multirow[t]{2}{*}{ Classes de Tamanhos } & \multicolumn{3}{|c|}{ Comprimento $(\mathrm{cm})$} \\
\hline & \multicolumn{3}{|c|}{ Localidades } \\
\hline & Areia & Usina & Arara \\
\hline Pequenas & $3,40 \mathrm{bA}^{1}$ & $2,80 \mathrm{aC}$ & $3,08 \mathrm{bB}$ \\
\hline Médias & 3,75 aA & $2,82 \mathrm{aC}$ & $3,40 \mathrm{aB}$ \\
\hline Grandes & $3,26 \mathrm{bA}$ & $2,46 \mathrm{bB}$ & $3,27 \mathrm{abA}$ \\
\hline
\end{tabular}

${ }^{1}$ Médias seguidas pela mesma letra minúscula na coluna e maiúscula na linha, não diferem entre si, pelo teste de Tukey a $5 \%$.

R. Árvore, Viçosa-MG, v.29, n.6, p.877-885, 2005 
Tabela 8 - Massa seca da raiz primária e dos cotilédones de plântulas de Mimosa caesalpiniifolia Benth. provenientes de diferentes localidades e com diferentes tamanhos

Table 8 - Dry matter of primary root and cotyledon of Mimosa caesalpiniifolia Benth. seedlings derived from different sites and with different sizes

\begin{tabular}{|c|c|c|c|c|c|c|}
\hline \multirow{3}{*}{$\begin{array}{l}\text { Classes de } \\
\text { Tamanhos }\end{array}$} & \multicolumn{3}{|c|}{ Raiz Primária (g/raiz) } & \multicolumn{3}{|c|}{ Cotilédones (g/cotilédone) } \\
\hline & \multicolumn{6}{|c|}{$\overline{\text { Localidades }}$} \\
\hline & Areia & Usina & Arara & Areia & Usina & Arara \\
\hline Pequenas & $0,003 \mathrm{cA}^{1}$ & $0,003 \mathrm{cA}$ & $0,003 \mathrm{cA}$ & $0,003 \mathrm{cA}$ & $0,003 \mathrm{cA}$ & $0,003 \mathrm{cA}$ \\
\hline Médias & $0,004 \mathrm{bA}$ & $0,004 \mathrm{bA}$ & $0,004 \mathrm{bA}$ & $0,005 \mathrm{bA}$ & $0,004 \mathrm{bB}$ & $0,004 \mathrm{bB}$ \\
\hline Grandes & 0,005 aA & $0,005 \mathrm{aAB}$ & $0,005 \mathrm{aB}$ & $0,006 \mathrm{aAB}$ & 0,007 aA & $0,006 \mathrm{aB}$ \\
\hline
\end{tabular}

${ }^{1}$ Médias seguidas pela mesma letra minúscula na coluna e maiúscula na linha, não diferem entre si, pelo teste de Tukey a $5 \%$.

Tabela 9 - Massa seca do hipocótilo de plântulas de Mimosa caesalpiniifolia Benth. provenientes de diferentes localidades e com diferentes tamanhos

Table 9 - Dry matter of hypocotyl of Mimosa caesalpiniifolia Benth. seedlings derived from different sites and with different sizes

\begin{tabular}{lc}
\hline Classes de Tamanhos & Massa Seca (g/Plântula) \\
\hline Pequenas & $0,0033 \mathrm{c}$ \\
Médias & $0,0044 \mathrm{~b}$ \\
Grandes & $0,0059 \mathrm{a}$ \\
\hline
\end{tabular}

Médias seguidas pela mesma letra não diferem entre si, pelo teste de Tukey a $5 \%$.

\section{CONCLUSÕES}

Pelos resultados deste estudo, conclui-se que:

* A germinação não foi influenciada pelo tamanho das sementes, no entanto, ela mesma foi fortemente influenciada pela procedência.

* O vigor das sementes apresentou relação direta com o seu tamanho, justificando-se a adoção de classes de tamanho para a formação de mudas.

\section{AGRADECIMENTOS}

Ao Engenheiro Agronômo Antônio Alves de Lima e aos laboratoristas Pedro Francisco da Silva, Rui Barbosa da Silva e Severino Francisco dos Santos, por terem viabilizado e execução deste trabalho.

\section{REFERÊNCIAS BIBLIOGRÁFICAS}

AGUIAR, F.F.A. et al. Influência do tamanho sobre a germinação de sementes de Caesalpinia echinata Lam. (pau-brasil). Revista Brasileira de Sementes, v.18, n.2, p.283-285, 1996.
ANDRADE, A.C.S.; VENTURI, S.; PAULILO, M.T. Efeito do tamanho das sementes de Euterpe edulis Mart. sobre a emergência e crescimento inicial. Revista Brasileira de Sementes, v.18, n.2, p.225-231, 1996.

\section{ASSOCIATION OF OFFICIAL SEED ANALYSTS -} AOSA - Seed vigor testing handbook. Saint Louis: 1983. 88p. (Handbook on Seed Testing, 32).

BARBOSA, R.I.; CAMPELLO, E.F.C. Efeito do tamanho das sementes na germinação, vigor e crescimento de plântulas de Eucalyptus grandis Hill ex-Maiden: In: CONGRESSO BRASILEIRO DE SEMENTES, 4., 1985, Brasília. Resumos ... Brasília: ABRATES, 1985. p.151.

BIRUEL, R.P. Caracterização e germinação de sementes de Caesalpinia ferrea Mart. ex. Tul. var. leiostachya Benth. 2001. 70f. Dissertação (Mestrado em Agronomia) Universidade Estadual Paulista, Jaboticabal, 2001.

BRASIL. Ministério da Agricultura e Reforma Agrária. Regras para análise de sementes. Brasília: SNDA/DNDV/CLAV, 1992.365p.

BROWN, R.F.; MAYER, D.G. A critical analysis of Maguire's germination rate index. Journal of Seed Technology, v.10, n.2, p.101-110, 1986.

CARneiro, J.G.A. Armazenamento de sementes florestais. Curitiba: DSM/UFPr, 1985. 40p.

CARVALHO, N.M.; NAKAGAWA, J. Sementes: ciência, tecnologia e produção. 4.ed. Jaboticabal: FUNEP, 2000. 588p.

R. Árvore, Viçosa-MG, v.29, n.6, p.877-885, 2005 
CASTRO, J.R.; DUTRA, A.S. Influência do tamanho das sementes de leucena (Leucaena leucocephala (Lam.) de Wit) cv. Cunningham na germinação e no vigor. Revista Brasileira de Sementes, v.19, n.1, p.88-90, 1997.

CLAIR, J.B.S.T.; ADAMS, W.T. Effects of seed weight and rate of emergence on early growth of open-pollinated Douglas-fir families. Forest Science, v.37, n.4, p.987-997, 1991.

DRUMOND, M.A. Potenciais das essências nativas do trópico semi-árido. In: CONGRESSO NACIONAL SOBRE ESSÊNCIAS NATIVAS, 1982, Campos do Jordão, 1982; Revista do Instituto Florestal, v.16, n.2, p.766-781.

FERREIRA, M.G.R.; TORRES, S.B. Influência do tamanho das sementes na germinação e no vigor de plântulas de Acacia senegal (L.) de Willd.

Revista Brasileira de Sementes, v.22, n.1, p.271-275, 2000.

FLEIG, F.D.; RIGO, S.M. Influência do tamanho dos frutos do palmiteiro Euterpe edulis Mart. Na germinação das sementes e crescimento das mudas. Ciência Florestal, v.8, n.1, p.35-41, 1998.

FRAZÃO, D.A.C. et al. Influência do peso da semente no desenvolvimento e vigor de mudas de cacau (Theobroma cacao L.). Revista de Agricultura, v.60, n.1, p.2-16, 1985.

FRAZÃO, D.A.C. et al. Tamanho da semente de guaraná e sua influência na emergência e no vigor. Revista Brasileira de Sementes, v.5, n.1, p.81-91, 1983.

GONZALEZ, E.J. Effect of seed size on germination and seedling vigor of Virola koschnyi Warb. Forest Ecology and Management, v.57, n.1-4, p.275-281, 1993.

GRAY, D.; STECKEL, J.R.A.; WARD, J.A. The effect of cultivar and cultural factors on embryosac volume and seed weight in carrot (Daucus carota L.). Annals of Botany, v.58, n.5, p.737744, 1986.

GROSS, K.L. Effects of seed size and growth form on seedling establishment of six monocarpic perennial plants. Journal of Ecology, v.72, n.2, p.369-387, 1984.

R. Árvore, Viçosa-MG, v.29, n.6, p.877-885, 2005
HAIG, D.; WESTOBY, M. Seed size, pollination casts and angiosperm success. Evolutionary Ecology, v.5, n.2, p.231-247, 1991.

KHARE, D.; SATPUTE, R.G. Influence of days to maturity and seed size on germination and seedling vigour in pigeonpea. Seed Research, v.27, n.2, p.170-173, 1999.

KRZYZANOWSKI, F.C.; VIEIRA, R.D.; FRANÇA NETO, J.B. Vigor de sementes: conceitos e testes. Londrina: ABRATES, 1999. 218p.

LEISHMAN, M.R.; WESTOBY, M. The role of large seed size in shaded conditions: experimental evidence. Functional Ecology, v. 8, n.2, p.205-214, 1994.

LEAL JÚNIOR, G.; SILVA, J.A.; CAMPELLO, R.C.B. Proposta de manejo florestal sustentado do sabiá (Mimosa caesalpiniaefolia Benth), Crato: IB AMA, 1999. 15p. (Boletim Técnico, 3).

LIN, S.S. Efeito do tamanho e maturidade sobre a viabilidade, germinação e vigor do fruto do palmiteiro. Revista Brasileira de Sementes, v.8, n.1, p.57-66, 1986.

LORENZI, H. Árvores brasileiras: manual de identificação e cultivo de plantas arbóreas nativas do Brasil. 3.ed. Nova Odessa: Instituto Plantarum, 2000. v.1.351p.

MAGUIRE, J. D. Speed of germination aid in selection and evaluation for seedling emergence and vigor. Crop Science, v.2, n.2, p.176-177, 1962 .

MARTINS, C.C.; CARVALHO, N.M.; OLIVEIRA, A.P. Quebra de dormência de sementes de sabiá (Mimosa caesalpiniaefolia Benth.) Revista Brasileira de

Sementes, v.14, n.1, p.5-8, 1992.

MARTINS, C.C. et al. Influência do peso das sementes de palmito-vermelho (Euterpe espiritosantensis Fernandes) na porcentagem e na velocidade de germinação. Revista Brasileira de Sementes, v.22, n.1, p.47-53, 2000. 
MENDES, B.V. Sabiá (Mimosa

caesalpiniaefolia Benth): valiosa forrageira arbórea e produtora de madeira das caatingas. Natal: UFRN, CPAMM, 1989.31p. (Coleção

Mossoroense, Série B, 1808).

MUÑOZ, G.; GIRALDO, G.; SOTO, J.F.

Descriptores varietales: arroz, frijol, maíz, sorgo. Colômbia: International Center for Tropical Agriculture - CIAT -, 1993. 174p.

POPINIGIS, F. Fisiologia da semente. 2. ed. Brasília: ABRATES, 1985. 298p.

RÊGO, F.A.O. et al. Influência do tamanho da semente e escarificação na germinação da macadamia (Macadamia integrifolia).

Informativo ABRATES, v.1, n.4, p.85, 1991.

RIBASKI, J. et al. Redução dos custos de reflorestamento na região nordeste, através do consórcio de espécies florestais, forragens e/ou agrícolas. Petrolina, CPATSA-PNPF, 1983. Relatório Anual Técnico.
SEDIYAMA, M.A.N. et al. Influência da origem e do tamanho da semente na germinação de madioquinha-salsa (Aracacia xanthorriza Banc.) Revista Brasileira de Sementes, v.13, n.2, p.127-129, 1991.

SILVA, A. et al. Influência do tamanho sobre a qualidade das sementes de Eucalyptus maculata Hook. Revista Brasileira de Sementes, v.16, n.2, p.187-190, 1994.

SURLES, S.E. et al. Relationships among seed weight components, seedling growth traits, and predicted field breeding values in slash pine.

Canadian Journal Forest Research, v.23, n.8, p.1550-1556, 1993.

TORRES, S.B. Influência do tamanho das sementes de Acacia gomifera no desenvolvimento das mudas. Agropecuária Catarinense, v.7, n.2, p.5, 1994.

VASCONCELOS, V.R. Caracterização química e degradação de forrageiras do semi-árido brasileiro no rúmem de caprinos. 1997. 89f. Tese (Doutorado em Zootecnia) - Universidade Estadual Paulista, Jaboticabal, 1997. 